\title{
Opportunities and Challenges for Effective Implementations of Karnali Province Health Policy
}

\author{
*Padam P. Simkhada ${ }^{1}$, Sharada Prasad Wasti ${ }^{2}$
}

\author{
Author Info: \\ ${ }^{1}$ Professor, School of Human and Health Science, University of Huddersfield, UK \\ ${ }^{2}$ Senior Research Fellow, School of Human and Health Science, University of Huddersfield, UK \\ *Corresponding Author: \\ Dr. Padam Prasad Simkhada, Email: P.P.Simkhada@hud.ac.uk \\ ORCID ID: https://orcid.org/0000-0002-5706-6479
}

\section{INTRODUCTION}

The health sector is complex, involving many stakeholders, multiple goals, and different beneficiaries. Health policy is an instrument to decide, plan and action that are undertaken to achieve health care goals within a society to combat the health problems. It is crucial for understanding it influences on health systems and prioritizing the health needs of the population. ${ }^{1}$

In 2015, Nepal became a federal republic and replaced a unitary government with a federal government at the central level, seven provincial and 753 local governments having more authority and resources in planning and managing than before. In the spirit of Constitution of Nepal 2015 and with the vision to make the health services of the country universal and qualitative, Ministry of Health and Population of Nepal (2019) revised National health policy in 2019. National Health policy 2019 of Nepal has expanded its plan and strategies according to federal structure of the country to improve health sector. ${ }^{2}$
The revision of health policy paved the way forward towards health system reform in the country which is further supported by Local Government Operation Act 2017.3 With the new governance structure, accountability has also been divided among the three tiers and the local level is responsible for the program implementation responsibilities. ${ }^{4} 5$ The Ministry of Health and Population is responsible for managing the health system at the federal level, whereas at the provincial level leads by the Ministry of Social Development and local governments metro/sub-metropolitan, municipality and rural municipality are responsible for its management. ${ }^{6}$ This indicates that the health system must gear up to meet the escalating healthcare needs of every citizen and upgrading the system as per the structure of the country.

Since 2015 in the changing administrative and managerial context of Nepal health system, many health policy related documents have been revised or newly created as per the spirit of the constitution of Nepal and each province has prepared plan and

Article Info
$\begin{aligned} & \text { Scan Me for Full Text } \\ & \text { Received: 28 March2021; }\end{aligned}$
How to cite this article in Vancouver Style?
Pimkhada PP, Wasti SP. Opportunities and Challenges for effective implementations of Karnali Province Health
Policy. Europasian J Med Sci. 2021; 3(1):i-iii. https://doi.org/10.46405/ejms.v3i1.312


policy as per the provincial needs. In 2019, the Karnali province has produced a separate health policy with eight guiding principles, 19 policy statements and 133 strategic plans with the moto of conscious, healthy, and well Karnali.?

The provincial health policy statements look more encouraging and pragmatic to address the provincial health needs. Policy broadly emphasized about the good governance, restructuring the health settings and ensure the basic and emergency health care to every citizen. Health services targeted to the ultramarginalised, child, disability, adolescent friendly including elderly care services. Policy also parleys about the importance of more accountable health service providers. Health facility should be made technology friendly promoting tele-health services and adopting electronic recording and reporting systems.

The Karnali Province has poor health indicators compare to other provinces. The policy has acknowledged such problems. In Karnali Province, half of health facilities offer all basic client services. While nearly all facilities in Karnali Province offer child curative care, child growth monitoring, modern methods of family planning and Antenatal Care (ANC), only $87 \%$ of facilities offer child vaccination services and 63\% offer services for Sexually Transmitted Infections (STIs). More than 6 in $10(62 \%)$ health facilities excluding HIV Testing and Counsellings (HTCs) in Nepal offer all 6 basic client services, including curative care for sick children, child growth monitoring, child vaccination, any modern method of family planning, ANC and services for STIs.

Health Policy of Karnali Province not limited to expand the specialised health services but also focuses on health behaviors related issues like tobacco and alcohol control program, quality control on food, rational use of medicine and monitoring of health services through Public health interventions. Likewise, school health promotion program through school nurse also stated. Policy also debates to raise awareness to minimize environmental health problems including climate change-induced health problems. It also envisions to promote a model health facility and health care providers for an effective health service.

Policy also has the provision to expand of the national health insurance program across the province and ensure the health care to the marginalized community by strengthening social security programs. Evidence based decision making process is also promoted and priority is given to improve and expand the health surveillance system including health related conferences. There is also the provision of the provincial disaster and health emergency response by making Provincial Health Emergency Operation Centre. It is also asserted that every three years this policy shall be reviewed and revised, and the provincial government will make a separate guidelines and plan for an effective implementation.

Some of the policy statements are very vague and looks more ambitious to translate into practices. For example, increase per-capita income and reach US $\$ 2100$ within five years of the policy implementation and within 10 years make one of the developed provinces in Nepal but it is not clear how to generate resources to meet those goal. Similarly, restructuring health facilities, making health facility technology friendly and implement those proposed number of new program activities are unclear how the resources (human, financial and capital) can be generated to reach those ambitious targets. Locallevel governments themselves act as mini-ministries, but the system still lacks clear direction, capacity, and clarity to drive and implementation of the health programmes effectively.

A policy should be framed, such that, it oversees the establishment of the Karnali Ayurvedic Academy. The aim of this academy should be to conduct studies, researches, and facilitate the production and processing of medicinal herbs.

In cooperation with the Government of Nepal, the Provincial Government shall develop regional teaching hospital and medical college. The same can be achieved by improving the standard of the regional hospital situated in Surkhet, which in turn will improve the quality of the basic health services provided to the citizens.

The regional teaching hospitals, and the Karnali Academy of Health Science shall make provisions to provide specialized and quality healthcare services. In addition to these specialized services, every district level hospitals should be equipped with at least 50 beds, while the local level hospitals should be equipped with a minimum of 15 beds.

The various Government hospitals will be encouraged to operate and manage their own pharmacies and laboratories. Oxygen plants shall be installed in remote districts such as Humla and Jumla, where there are still no proper means of transportation. ${ }^{7}$

The Provincial Government should look to develop and expand the Ayurveda method of treatment, 
and other alternative methods of treatment as well. To achieve the same, a feasibility study shall be conducted, the findings of which will assist the Government in establishing regional Ayurveda hospitals.

We shall encourage the establishment of a medical industry, which should be possible, if we manage to establish a partnership between the private sector and the community.

The provisions for creating emergency healthcare service funds shall be continued. To make healthcare services efficient and reliable, provisions for doctors, medicines, and airlifting services should be made without fail. These healthcare services shall be based purely on the findings of a feasibility study conducted on health police, non-security custody, and airambulance. Also, we shall prepare procedures for continuing the airlifting services.

Various healthcare service programs pertaining to safe motherhood, childcare, and control of communicable and non-communicable diseases; shall be conducted throughout the province. In order to ensure the safety and security of the healthcare workers, a certain code of conduct needs to be established

\section{Ways Forward}

The Karnali health policy represents an important milestone and offer encouraging signs, but there are a number of challenges to translate these into practice. Policy documents provide ample opportunities to change the healthcare system, but the Karnali province government should ensure strategic planning and guidelines, and identify sustainable means of resources - trained personnel, uninterrupted logistic supply and funding - to ensure access of quality health care for every citizen. There should have a solid implementation plan and action on restructuring the health facilities and make closure of the health facility to the community. There are of course needs a dynamic leadership and a strategic vision to implement and achieve the policy goals and targets to improve the health of Karnali province. Therefore, early and active case detection activities, verification and validation of records/reports of local health facility level/municipalities and capacity building of health workers are undergoing but need to be escalated to obtain the goal mentioned in policy documents. There is a need to expand services for early detection of hidden and undiagnosed cases.

A multisectoral action is required to achieve the goal and objectives as illustrated in health policy. There should be access to and logistics for medicines, as well as enhanced activities for advocacy, capacity strengthening and adequate funding. Community based activities and applied research are pivotal to bridge the gap in between policy formulation and implementation.

\section{REFERENCES}

1. Marasini B. Health System Development in Nepal. Journal of the Nepal Medical Association 2020;58(221)

2. Government of Nepal. Local government operation act, 2017.

3. Ministry of Health and Population. National health policy 2019. Ministry of Health and Population. https://dohs.gov.np/nationalhealth-policy-2074/

4. Thapa R, Bam K, Tiwari P, et al. Implementing federalism in the health system of Nepal: opportunities and challenges. International journal of health policy and management 2019;8(4):195.

5. MoL. Constitution of Nepal 2015. Kathmandu: Constituent Assembly Secretariat, 2015.

6. DoHS. Annual report: department of health services 2075/76 (2018/19). Kathmandu: Kathmandu: Ministry of Health and Population, Department of Health Services 2020.

7. MoSD. Karnali Provience Health Policy 2076. Surkhet: Ministry of Social Development, Karnali Province 2019. 